\title{
REVIEWS.
}

PULMONARY TUBERCULOSIS IN GENERAL PRACTICE.

By ANDrew Morland, M.D., M.R.C.P. Messrs. John Bale, Sons \& Danielsson, Ltd. Price 2/6.

In many respects this is an excellent little book for the general practitioner as an introduction to the very wide subject of pulmonary tuberculosis. The reader of this book will derive a considerable amount of valuable practical information which will assist him in dealing with the large number of cases of this disease which are inevitably met with in practice. The views expressed are, on the whole, well balanced and, it may be said, generally accepted.

In view of the significance of the radiological examination of the chest in pulmonary tuberculosis-it is really part of the clinical examination - it is to be regretted that the writer has not included any X-ray illustrations.

$\mathrm{X}$-ray examination of the chest is, of course, a specialised subject, but no work in pulmonary tuberculosis can be regarded as complete, even for the general practitioner, without some illustrations to assist him in interpreting (of course only to a limited degree) radiograms of the chest.

Apart from this, the book is to be highly recommended for the general practitioner in search of a small practical handbook dealing with this wide-spread disease.

\section{DISEASES OF WOMEN.}

By Ten Teachers. Fifth Edition. London :

Edward Arnold \& Co. Price 18/- net.

We welcome the fifth edition of this wellknown text-book, which has been brought up to date by the incorporation of recent work on endocrinal activity. As is pointed out by the authors, new facts are constantly coming to light, and repeated revision is required for their interpretation. They emphasize that, in spite of the close connection existing between the ductless glands and the development and functions of the genital system, the number of cases in which a profitable use of the glands or their extracts can be made is not great.

In dealing with carcinoma of the cervix, it is not indicated whether the results of radium and deep X-ray therapy compare favourably or otherwise with those obtained by surgical methods, but the statement is made that neither fixation of the uterus nor the presence of palpable glands in the pelvis is alone regarded as a contra-indication to operative treatment.

This edition is an advance on its predecessors, excellent as these were. The subject matter is well arranged, the type is good, while the illustrations are numerous and clear. The hope of the authors, that a well-balanced account of modern thought and practice in gynæcology would be provided in this book, is abundantly justified.

\section{AIDS TO OPERATIVE SURGERY.}

By Cecil P. G. Wakeley, D.Sc., F.R.C.S. Baillière, Tindall \& Cox. 1934. Price 3/6.

This is obviously a book for candidates going up for examinations, and it is surprising how full of information it is. On the other hand, such a book cannot be expected to be of much use to the practising surgeon, nor is it intended to be. There are one or two errors that might be eradicated in future editions. For instance, in describing the operation for cholecystectomy, we do not think that the advice to close the abdomen completely, provided there is little or no oozing from the denuded surface of the liver, is sound, and especially is this advice dangerous from the point of view of a candidate. Again, in the section on operations on the thyroid gland, there is the following sentence: "It is usually necessary to divide the attachments of the sterno- and thyro-hyoids." We do not think that this advice is either necessary or correct. Again, in Dunn's operation, as usually practised, the three cuneiform bones are not removed, but only each proximal, cartilaginous surface.

In a work of this character, however, errors are bound to creep in, and we can recommend this book to the student who is anxious to read about operations in the smallest space available. Whether such "cram" books are for the ultimate good of medical education, is a matter that the Reviewer does not care to discuss here. 